\begin{tabular}{llll} 
Abstract PTU-39 Table 1 & & & \\
\hline Findings at Endoscopy & 2WW & Urgent & Total \\
\hline Normal & 35 & 20 & 55 \\
Benign pathology & 92 & 26 & 118 \\
$\begin{array}{l}\text { Inflammatory pathology e.g. IBD } \\
\text { Low risk pre-malignant (e.g. low risk }\end{array}$ & 5 & 6 & 11 \\
polyps) & 25 & 12 & 37 \\
High risk pre-malignant (e.g. advanced & 8 & 6 & \\
polyps) & & & 14 \\
Localised malignancy & 18 & 8 & 26 \\
$\begin{array}{l}\text { Disseminated malignancy } \\
\text { Incomplete examination }\end{array}$ & 7 & 0 & 7 \\
\hline
\end{tabular}

[1]. The data were collected and analysed in May 2021 using Microsoft Excel.

Results 108 patients were already on $2 \mathrm{WW}$ at the start of this period and 204 patients were referred for $2 \mathrm{WW}$ endoscopy during this period. 119 patients were referred on an urgent pathway. Nearly a quarter of both groups did not have the procedure they were referred for $(72 / 312$ 2WW, 28/108 Urgent). 1 patient on the $2 \mathrm{WW}$ pathway cancelled their procedure and was later found to have cancer. The mean and median wait times were 80 and 71 days, respectively.

Conclusions We detected cancers in $8 \%$ of the referrals, which is higher than historical national rates of between $3.1-4.1 \%$ [4]. This supports the conclusions from Rutter et al that patients did not seek diagnostic services during this time period [3]. Most of our patients were waiting nearly 3 months for their procedure. It is unclear what impact this will have for their further management, at this time. This period will likely be examined in the years to come to assess for the ultimate cost that patients may have borne as a result of the COVID-19 pandemic.

\section{PTU-40 SURVEILLANCE ENDOSCOPY IN ELDERLY PATIENTS: AN AVENUE FOR COST-SAVING AND REDUCING SERVICE BURDEN}

Shi Jie Looi*, Debabrata Majumdar. Ashford and St. Peter's Hospitals NHS Foundation Trust, Chertsey, UK

\subsection{6/gutjnl-2021-BSG.113}

Introduction In recent years, there has been increasing strain on endoscopy services with increasing activity and consequently, fewer services being able to meet waiting time targets ${ }^{1}$. Disruption to services during the COVID-19 pandemic have also led to a significant increase in the backlog of patients, further exacerbating the problem ${ }^{2}$. We attempt to reduce the burden of this issue at our organisation by reviewing the indication for surveillance of elderly patients against existing national guidelines $3,4,5$.

Methods The list of patients due for surveillance endoscopy was obtained from the endoscopy department database. Inclusion criteria was simply age equal to 80 or above. One author scrutinised electronic case records, reviewing previous endoscopy reports and clinic letters to determine the indication for surveillance. If this was not consistent with national guidelines $3,4,5$, the procedure would be cancelled after discussion and with patient consent.
Results The most common indication for surveillance gastroscopy and colonoscopy was Barrett's oesophagus (89\%) and previous polypectomy (70\%) respectively. From 168 patients reviewed, 75 colonoscopies, 1 flexible sigmoidoscopy and 1 gastroscopy were cancelled. This translates to a cost saving of between $£ 35159$ - $£ 44$ 461. The most common reasons for removal from surveillance were: indication not in keeping with current guidelines (90\%), patient preference (4\%) and frailty (4\%).

Conclusions Our study highlights an easily transferable model to achieve cost savings and reduce unnecessary surveillance endoscopy whilst ensuring quality is maintained by adhering to current national guidelines. These savings could then be utilised to increase service capacity in order to help address the problem of increasing burden on endoscopy services.

\section{REFERENCES}

1. Ravindran $S$, Bassett $P$, Shaw $T$, et al. National census of UK endoscopy services in 2019. Frontline Gastroenterology Published Online First: 24 June 2020. doi:10.1136/flgastro-2020-101538

2. Rutter MD, Brookes M, Lee TJ, et al. Impact of the COVID-19 pandemic on UK endoscopic activity and cancer detection: a National Endoscopy Database Analysis. Gut 2021;70:537-543.

3. Rutter MD, East J, Rees CJ, et al. British Society of Gastroenterology/Association of Coloproctology of Great Britain and Ireland/Public Health England post-polypectomy and post-colorectal cancer resection surveillance guidelines. Gut 2020;69:201-223.

4. Fitzgerald RC, di Pietro M, Ragunath K, et al. British Society of Gastroenterology guidelines on the diagnosis and management of Barrett's oesophagus. Gut 2014;63:7-42

5. Cairns SR, Scholefield JH, Steele RJ, et al. Guidelines for colorectal cancer screening and surveillance in moderate and high risk groups (update from 2002). Gut 2010;59:666-689

\section{PTU-41 MAINTAINING ERCP CAPACITY AND HIGH QUALITY KEY PERFORMANCE QUALITY INDICATORS DURING THE CHALLENGE OF COVID-19}

Ioannis Varbobitis*, Lewis Bulman, Dileep Lobo, Glen Irving, Steve Ryder, Guru Aithal, Suresh Venkatachalapathy, Adolfo Parra-Blanco, Martin James. NIHR Nottingham Biomedical Research Centre, Nottingham University Hospitals NHS Trust and the University of Nottingham, Nottingham, UK

\subsection{6/gutjnl-2021-BSG.114}

Introduction COVID-19 has negatively impacted on the delivery of endoscopy services worldwide. In the UK, national endoscopy database (NED) indicated activity was dramatically reduced by $80-95 \%$ during the first wave in 2020, due to redeployment of staff, challenges with personal protective equipment (PPE), room air-change cycle and patients' unwillingness to attend during lockdown restrictions. ERCP is a higher-risk procedure often performed in patients with an urgent indication such as cancer obstruction or gallstonerelated biliary sepsis or pancreatitis. We aimed to define the impact of COVID-19 on our ERCP service delivery, clinical outcomes, patient safety and endoscopists' KPIs.

Methods We examined Nottingham ERCP outcomes during the COVID-19 pandemic in 2020 compared to those before in 2019 at a high-volume HPB endoscopy centre serving a local population of 750,000 and tertiary HPB MDT population of 2.3 million. Technical success, comfort rates and complications according to RCP JAG and ESGE quality standards, including 8- and 30-day readmission rates and deaths were recorded. We also assessed the incidence of Covid-19 infection among the population who underwent ERCP. 